\title{
Assembly of Short-Chain Amphiphilic Homopolymers into Well-Defined Particles
}

\author{
Stephanie Swan, ${ }^{a}$ Franklin O. Egemole, ${ }^{a}$ SonBinh T. Nguyen, ${ }^{b, *}$ Jun-Hyun Kim ${ }^{a, *}$ \\ ${ }^{a}$ Department of Chemistry, Illinois State University, Normal, Illinois 61790-4160 \\ ${ }^{b}$ Department of Chemistry and the International Institute for Nanotechnology, Northwestern \\ University, Evanston, IL 60208
}

Materials. Bicyclo[2.2.1]hepta-2,5-diene (2,5-norbornadiene, 98\%), hexanes (>95\%), methanol $(\mathrm{MeOH},>99 \%)$, potassium hydroxide $(\mathrm{KOH},>85 \%)$, sulfuric acid $(95 \%)$, benzene (99\%), potassium thiocyanate (KSCN, >99\%), ethylene glycol (>99\%), cyclohexane (>99\%), potassium carbonate $\left(\mathrm{K}_{2} \mathrm{CO}_{3},>99 \%\right)$, and Grubbs catalyst $\left(\left(\mathrm{PCy}_{3}\right)_{2} \mathrm{Cl}_{2} \mathrm{Ru}=\mathrm{CHPh}, 1^{\text {st }}\right.$ generation) were purchased from Aldrich Company. Sodium hydroxide $(\mathrm{NaOH})$, hydrochloric acid $(\mathrm{HCl})$, acetic acid (Glacial), sodium carbonate anhydrous $\left(\mathrm{Na}_{2} \mathrm{CO}_{3}\right)$, potassium permanganate $\left(\mathrm{KMnO}_{4},>99 \%\right)$, ethanol $(\mathrm{EtOH}, 100 \%)$, chloroform $\left(\mathrm{CHCl}_{3}\right)$, tetrahydrofuran (THF), sodium sulfite $\left(\mathrm{Na}_{2} \mathrm{SO}_{3}\right)$, exo-bicyclo(2.2.1)hept-5-ene-2-methanol (NBE-MeOH, $>98 \%$ ), and bicyclo(2.2.1)hept-5-ene-2-exo,3exo-dimethanol [NBE-(MeOH)2, >97\%] were obtained from Fischer Scientific. All chemicals were used as received. All other anhydrous solvents were dried over neutral alumina via the Dow-Grubbs solvent system. ${ }^{1}$ The syntheses of the monomers and polymers were carried out at room temperature either in a $\mathrm{N}_{2}$-filled glovebox or using standard Schlenk techniques, unless otherwise noted. The water used in all reactions was either deionized water or highly purified to a resistance of $18 \mathrm{M} \Omega$ (Academic Milli-Q Water System; Millipore Corporation) and filtered through a $0.22 \mu \mathrm{m}$ membrane to remove any impurities. All glassware was cleaned with aqua regia and then with a strong base (saturated $\mathrm{KOH}$ in isopropyl alcohol) before use. Deuterated solvents (Cambridge Isotope Laboratories) were purchased from commercial sources and used as received. All column chromatography was carried out using a silica gel (230-400 mesh, purchased from Sorbent Technologies; Atlanta, GA) under the positive pressure of lab air.

\section{Synthesis of 5-exo-norbornene-2-ol (NBE-OH)}

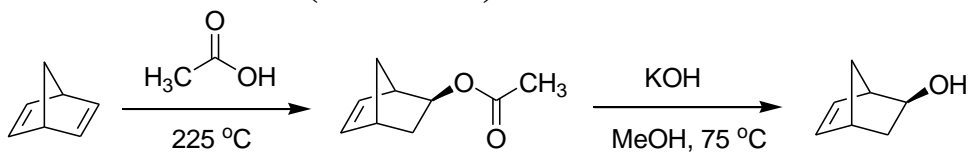

Initially, 5-exo-norbornene-2-yl acetate was sysnthesized using 2,5-norbornadiene (17.1g, $185.4 \mathrm{mmol})$ and acetic acid $(20.4 \mathrm{~g}, 134 \mathrm{mmol})$ in a $500 \mathrm{~mL}$ pressure tube. The pressure tube was placed in a Dewar containing liquid $\mathrm{N}_{2}$ to freeze the mixture, forming a white solid, purged with $\mathrm{N}_{2}$ (g) for $5 \mathrm{~min}$, and then capped with a lid. The mixture was slowly warmed up to room temperature, followed by a repetition of the freeze and purge cycle. The mixture was then placed in a sandbath and heated to $225{ }^{\circ} \mathrm{C}$ for $24 \mathrm{~h}$. The final solution was cooled to room temperature and poured into a $500 \mathrm{~mL}$ separatory funnel; this was followed up with the addition of saturated $\mathrm{Na}_{2} \mathrm{CO}_{3}(\sim 200 \mathrm{~mL})$. The aqueous solution was separated, extracted with hexanes $(200 \mathrm{~mL} \times 3)$, and dried over anhydrous $\mathrm{Na}_{2} \mathrm{SO}_{4}$. The solvent was filtered and evaporated under a vacuum to give a $72 \%$ yield of 5-exo-norbornene-2-yl acetate as a thick yellow oil. The spectroscopic data for the product were in good agreement with the data from the literature. ${ }^{2-3}$ ${ }^{1} \mathrm{H}$ NMR $\left(500 \mathrm{MHz}, \mathrm{CDCl}_{3}\right.$ ): $\delta$ 1.4-1.8 (m, 4H, H3 and H7), $2.05\left(\mathrm{~s}, 3 \mathrm{H}, \mathrm{CH}_{3}\right), 2.87-2.90(\mathrm{~m}$, 2H, H1 and H4), 4.67 (m, 1H, H2: -CH-OAc), 6.00-6.25 (dd, 2H, H5 and H6). GC-MS (EI): $\mathrm{m} / \mathrm{z}=152\left(\mathrm{C}_{9} \mathrm{H}_{12} \mathrm{O}_{2}\right)$. 
5-exo-norbornene-2-ol (NBE-OH) was then prepared according to the procedure found in the literature. ${ }^{3} \mathrm{KOH}(25 \mathrm{~g}, 445.6 \mathrm{mmol}), \mathrm{MeOH}(200 \mathrm{~mL})$ and 5-exo-norbornene-2-yl acetate (8.0 g, $52.6 \mathrm{mmol}$ ) were mixed in a $500 \mathrm{~mL}$ round-bottom flask equipped with a magnetic stir bar and reflux condenser. The mixture was stirred and refluxed at $75^{\circ} \mathrm{C}$ for $8 \mathrm{~h}$ under air. After cooling to room temperature, the mixture was transferred to a $1000 \mathrm{~mL}$ separatory funnel and extracted with diethyl ether $(400 \mathrm{~mL})$. The ether layer was washed with water $(400 \mathrm{~mL} \times 3)$ and the aqueous layer was washed with ether $(\sim 400 \mathrm{~mL} \times 2)$. The organic layers were combined, dried over sodium sulfate, filtered, and evaporated under a vacuum, eventually yielding a light yellow powder. The powder was subjected to column chromatography $(5.5 \mathrm{~cm}$ x $30 \mathrm{~cm}, 3: 7$ ether:hexanes). The isolated product of NBE-OH appeared as a white solid (2.5 g, $22.7 \mathrm{mmol}$, $43 \%)$. The spectroscopic data for $\mathrm{NBE}-\mathrm{OH}$ were in good agreement with the data in the literature. ${ }^{3-4}{ }^{1} \mathrm{H}$ NMR (500 MHz, $\mathrm{CDCl}_{3}$,): $\delta$ 1.27-1.75 (m, 4H, H3 and $\left.\mathrm{H} 7\right), 2.73-2.83(\mathrm{~d}, 2 \mathrm{H}$, $\mathrm{H} 1$ and $\mathrm{H} 4), 3.91-3.92(\mathrm{~m}, 1 \mathrm{H}, \mathrm{H} 2$ : $-\mathrm{CH}-\mathrm{OH}), 5.96-6.18$ (m, 2H, H5 and H6). GC-MS (EI): $\mathrm{m} / \mathrm{z}=110\left(\mathrm{C}_{7} \mathrm{H}_{10} \mathrm{O}\right)$.

\section{Synthesis of 5-exo-cis-norbornene-2,3-diol (NBE-diols)}

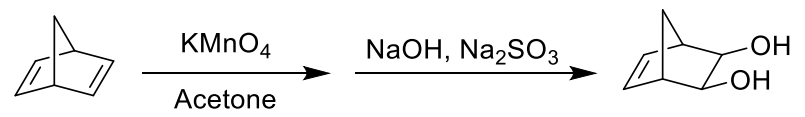

5-exo-cis-norbornene-2,3-diol (NBE-diols) was prepared using a slightly modified procedure found in the literature. ${ }^{5} 12.5 \mathrm{~mL}$ of freshly redistilled norbornadiene $(11.3 \mathrm{~g}, 122$ mmol) was mixed in dry acetone $(110 \mathrm{~mL})$ and was chilled to $-72{ }^{\circ} \mathrm{C}$ using an acetone-dry ice bath with vigorous stirring. Over a period of 10 minutes, finely powdered potassium permanganate $(7.9 \mathrm{~g}, 50 \mathrm{mmol})$ was slowly added to the reaction mixture while the temperature of solution was maintained between -64 and $-70{ }^{\circ} \mathrm{C}$. After stirring for $1 \mathrm{~h}$, a precooled solution $\left(0{ }^{\circ} \mathrm{C}\right)$ containing $\mathrm{NaOH}(2.0 \mathrm{~g}), \mathrm{Na}_{2} \mathrm{SO}_{4}(2.5 \mathrm{~g})$, and water $(35 \mathrm{~mL})$ was added the reaction mixture in portions over $5 \mathrm{~min}$ and stirred for $10 \mathrm{~min}$. The reaction mixture was then allowed to warm to room temperature over 2 hours, resulting in a solution containing thick brown solid. The supernatant was collected and the solid was extracted with $90 \%$ acetone-water solution (50 $\mathrm{mL} \times 3)$. The combined liquid was evaporated under a vacuum at $35^{\circ} \mathrm{C}$ to remove the acetone layer. The aqueous residue was saturated with $\mathrm{NaCl}$ and extracted with $\mathrm{CHCl}_{3}(25 \mathrm{~mL} \times 4)$. The chloroform extract was dried with $\mathrm{Na}_{2} \mathrm{SO}_{4}$ and evaporated under vacuum at $35{ }^{\circ} \mathrm{C}$. The oily product was stirred overnight in a mixture of cyclohexane $(10 \mathrm{~mL})$ and a few drops of $\mathrm{CHCl}_{3}$. The tan solid was removed by gravity filtration and washed with warm cyclohexane. The product after vacuum drying for $1 \mathrm{~h}$ resulted in a slightly lower than $10 \%$ yield. The spectroscopic data for the NBE-diols were in good agreement with the data from the literature (except the alcohol peak from the NMR spectrum). $1 \mathrm{H} \mathrm{NMR}\left(500 \mathrm{MHz}, \mathrm{CDCl}_{3}\right.$,): $\delta 1.61$ (m, H7), 1.85 (m, H7), 2.68 (m, H1 and H4), 2.72 (broad, OH) 3.69 (m, H2 and H3), 6.02 (t, H5 and H6). GC-MS (EI): $\mathrm{m} / \mathrm{z}=126\left(\mathrm{C}_{7} \mathrm{H}_{10} \mathrm{O}_{2}\right)$. 


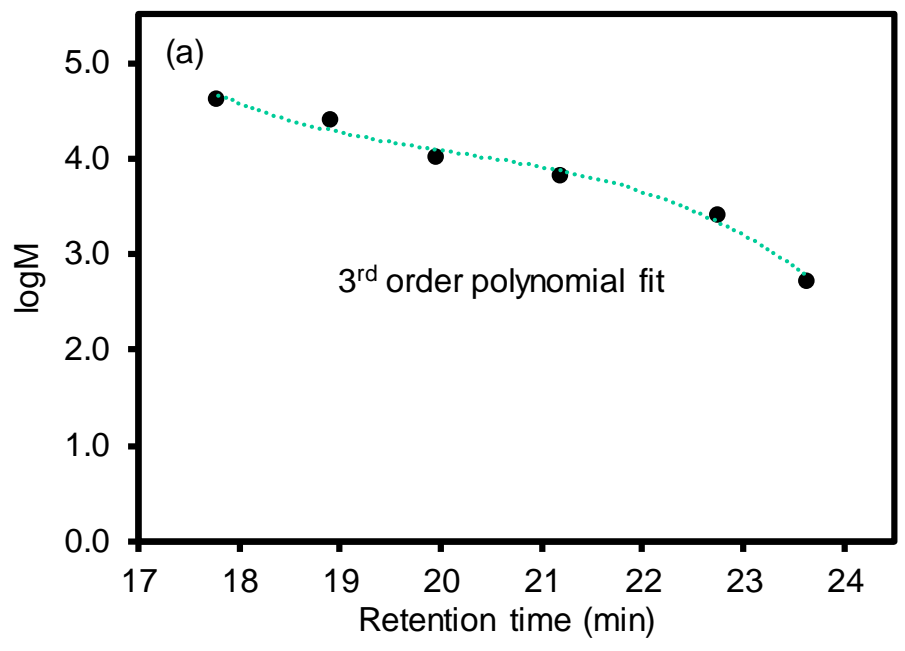

(b)
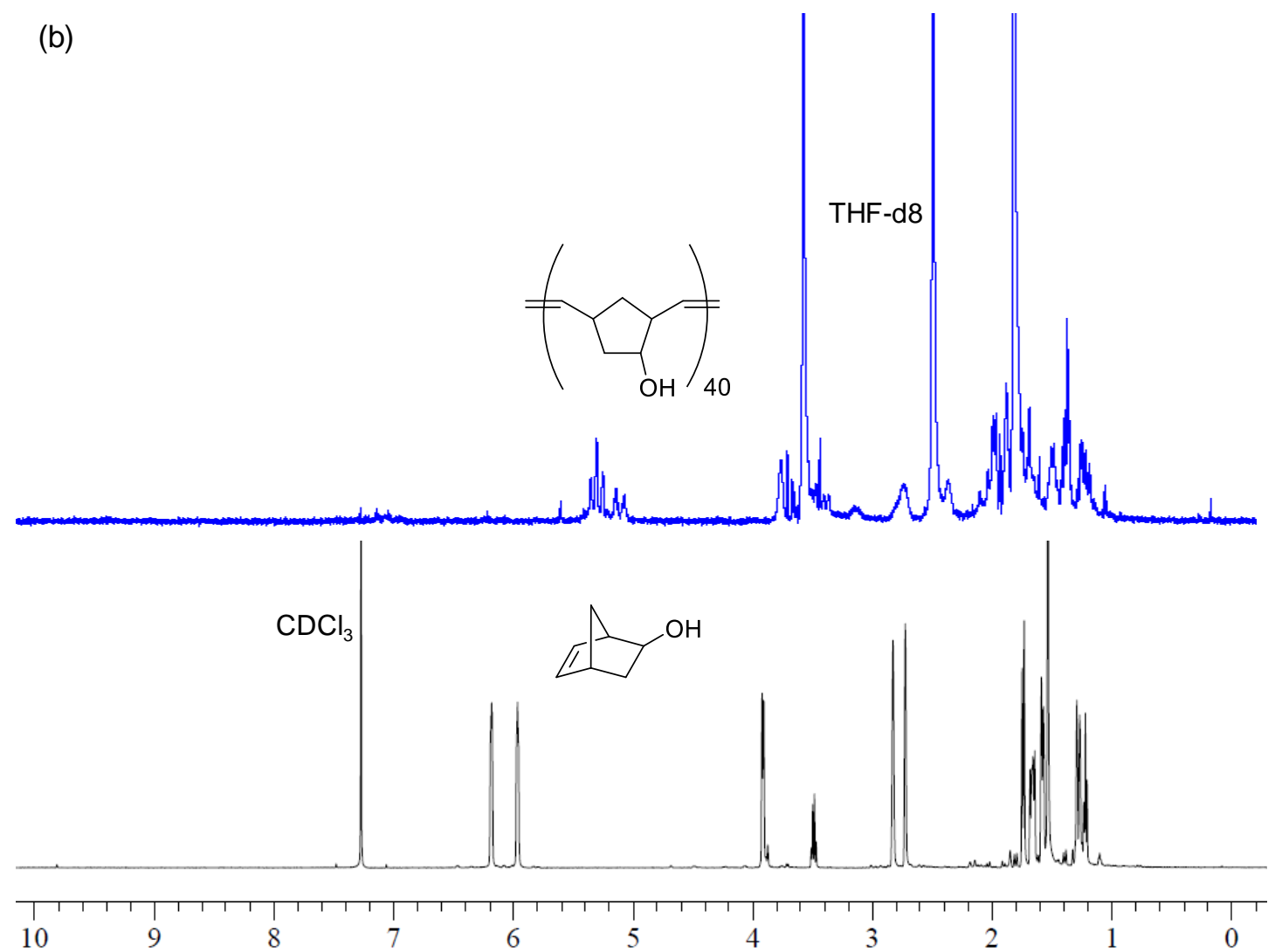

Figure S1. (a) GPC calibration curve fitted with a common polynomial function, ${ }^{6-7}$ and (a) NMR spectra of NBE-OH and 40 mers of poly(NBE-OH). Note) The definite peak assignments for the poly(NBE-OH) were difficult due to the weak intensity and poor resolution. 

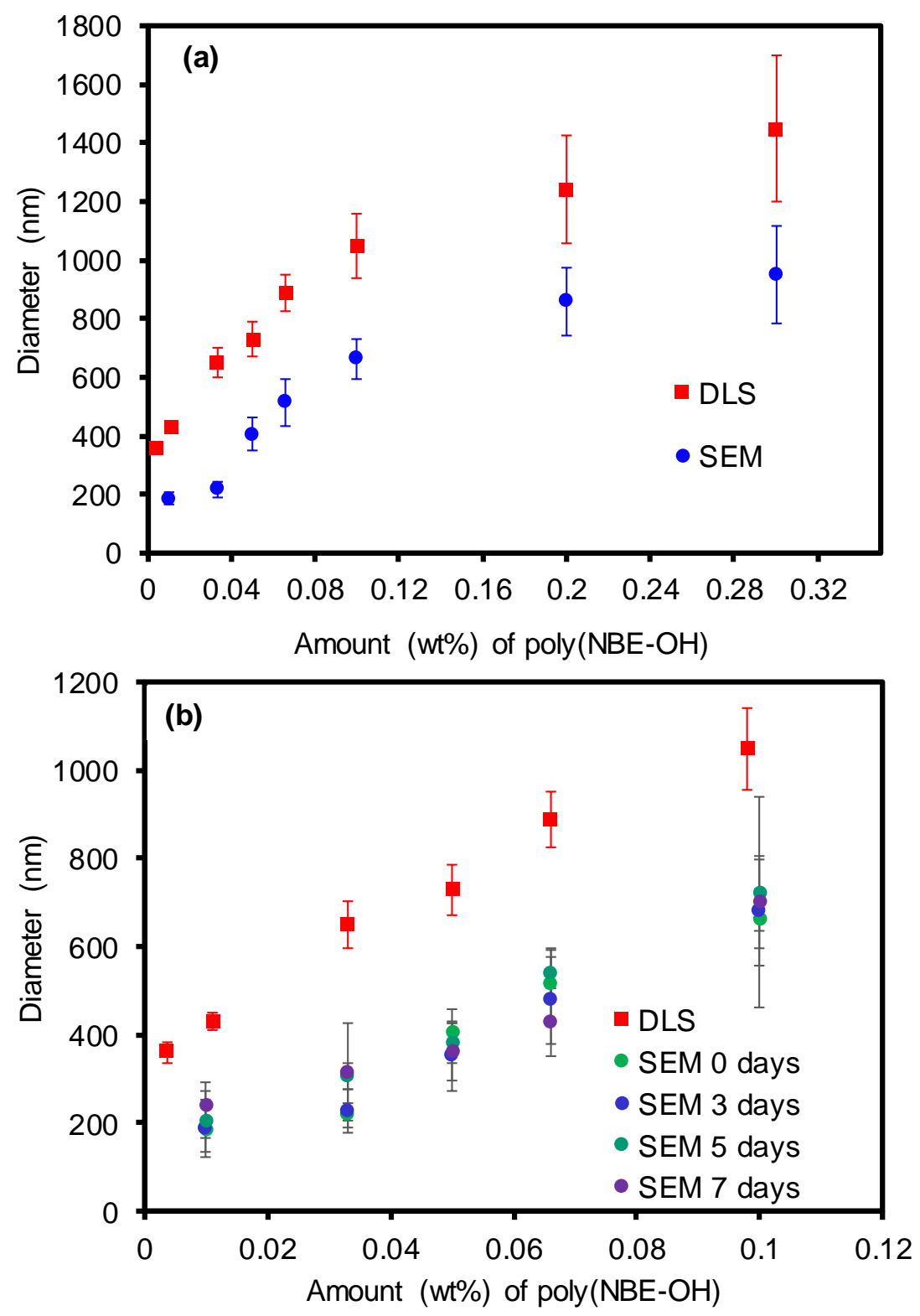

Figure S2. Diameter changes for 40 mers of poly(NBE-OH) with the increase of the polymer concentration in MeOH examined by DLS and SEM: (a) initial and (b) as a function time. 

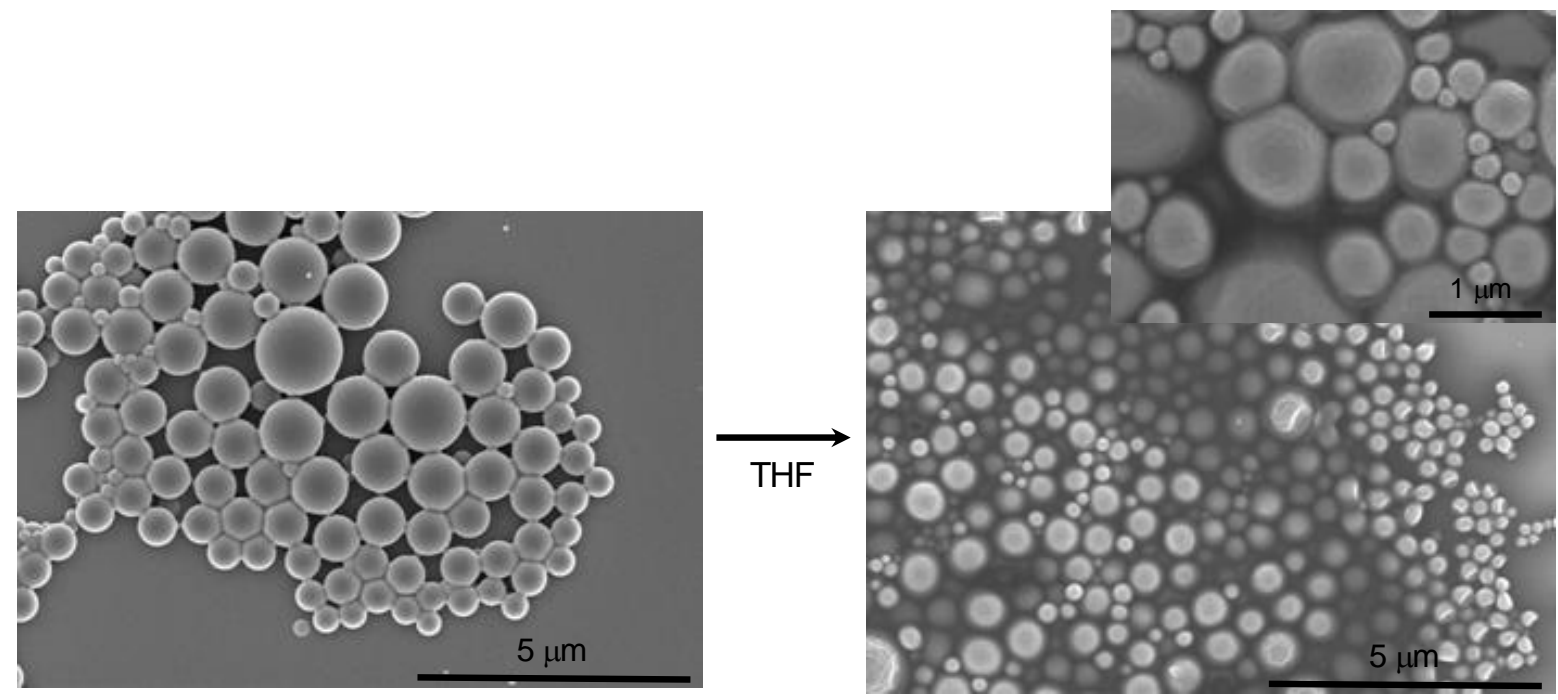

Figure S3. SEM images of $0.2 \mathrm{wt} \%$ poly(NBE-OH) (40 mers) and in situ SEM images of poly(NBE-OH) particles after treatment with THF.

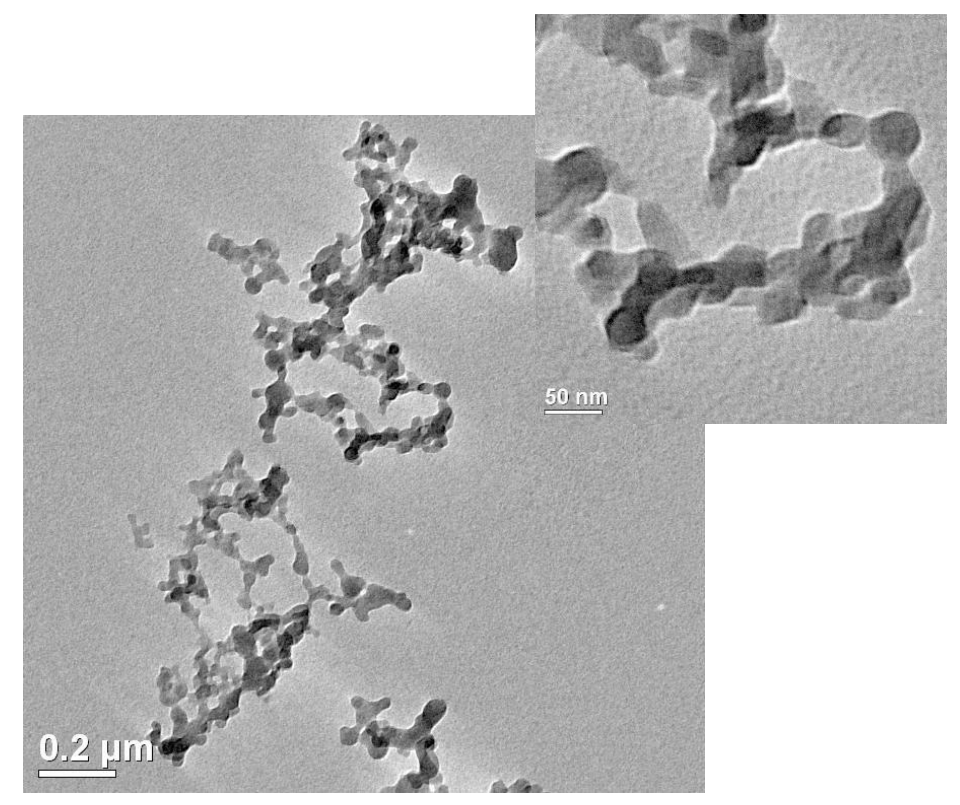

Figure S4. TEM images of poly(NBE-OH) after staining with phosphotungstic acid. 


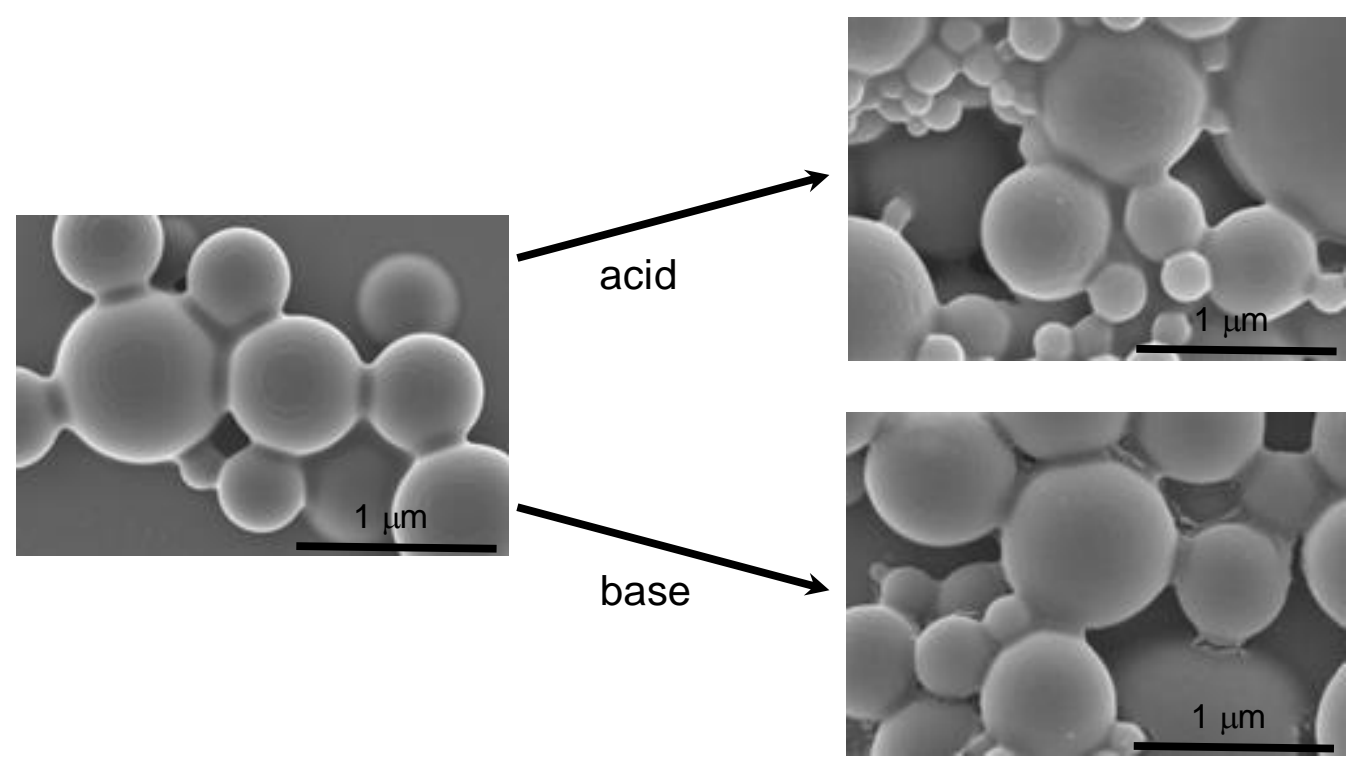

Figure S5. SEM images of $0.2 \mathrm{wt} \%$ poly(NBE-OH) (40 mers) and in situ SEM images of poly(NBE-OH) particles after treatment with $0.1 \mathrm{M} \mathrm{HCl}$ and $0.1 \mathrm{M} \mathrm{NaOH}$ solutions.
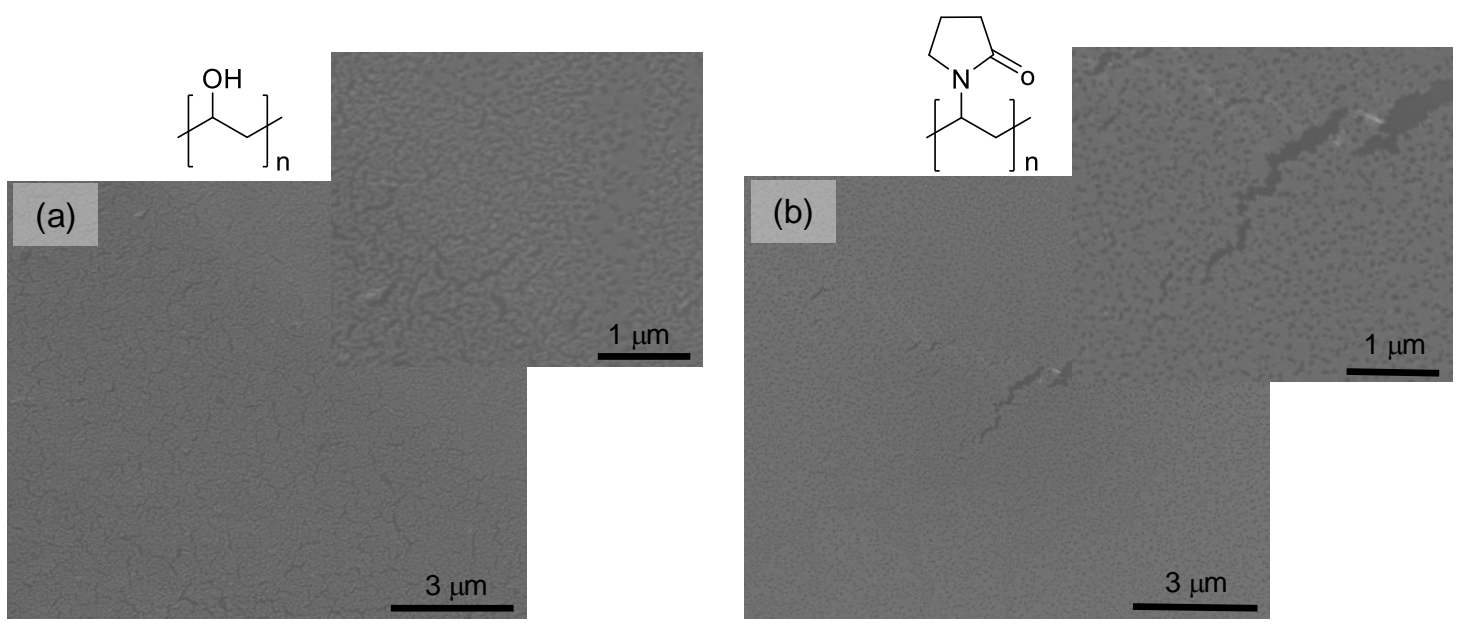

Figure S6. SEM images of $0.1 \mathrm{wt} \%$ (a) polyethylene glycol (PEG, $40 \mathrm{kDa}$ ) and (b) polyvinylpyrrolidone $(10 \mathrm{kDa})$ prepared $\mathrm{MeOH}$. 


\section{References}

1. Pangborn, A. B.; Giardello, M. A.; Grubbs, R. H.; Rosen, R. K.; Timmers, F. J., Safe and Convenient Procedure for Solvent Purification. Organometallics 1996, 15, 1518-1520.

2. Cristol, S. J.; Morrill, T. C.; Sanchez, R. A., Bridged Polycyclic Compounds. XLI. The Uncatalyzed Addition of Acetic Acid to Norbornadiene. J. Org. Chem. 1966, 31, 2733-2737.

3. Posner, G. H.; Ting, J. S.; Lentz, C. M., A Mechanistic and Synthetic Study of Organocopper Substitution Reactions with Some Homoallylic and Cyclopropylcarbinyl Substrates : Application to Isoprenoid Synthesis. Tetrahedron 1976, 32, 2281-2287.

4. Bain, J. P.; Best, A. H.; Hampton, B. L.; Hawkins, G. A.; Kitchen, L. J., Nopol. II. Syntheses in the Apocamphane Series. The Preparation of Optically Pure 1-Camphene. J. Am. Chem. Soc. 1950, 72, 3124-3127.

5. Shealy, Y. F.; Clayton, J. D., Synthesis of Carbocyclic Analogs of Purine Ribonucleosides. J. Am. Chem. Soc. 1969, 91, 3075-3083.

6. Hong, P.; Koza, S.; Bouvier, E. S., Size-Exclusion Chromatography for the Analysis of Protein Biotherapeutics and their Aggregates. J. Liq. Chromatogr. Relat. Technol. 2012, 35 , 2923-2950.

7. Normand, V.; Avaltroni, F.; Bouquerand, P. E., Mathematical Discretization of SizeExclusion Chromatograms Applied to Commercial Corn Maltodextrins. J. Chromatogr. Sci. 2006, 44, 91-95. 